Research Article

\title{
Investigations into the Rock Dynamic Response under Blasting Load by an Improved DDA Approach
}

\author{
Biting Xie $\mathbb{D}^{1,},{ }^{1,2}$ Xiuli Zhang $\mathbb{D D}^{1}{ }^{1}$ Hao Wang $\mathbb{D}^{1},{ }^{1}$ Yuyong Jiao, ${ }^{3}$ and Fei Zheng $\mathbb{D}^{4}$ \\ ${ }^{1}$ State Key Laboratory of Geomechanics and Geotechnical Engineering, Institute of Rock and Soil Mechanics, \\ Chinese Academy of Sciences, Wuhan 430071, China \\ ${ }^{2}$ University of Chinese Academy of Sciences, Beijing 100049, China \\ ${ }^{3}$ China University of Geosciences, Wuhan 430074, China \\ ${ }^{4}$ Faculty of Mathematics and Physics, Leibniz University Hannover, Hannover 30167, Germany
}

Correspondence should be addressed to Xiuli Zhang; zxl@whrsm.ac.cn

Received 24 July 2020; Revised 12 January 2021; Accepted 25 January 2021; Published 8 February 2021

Academic Editor: Dr Vasant Matsagar

Copyright (c) 2021 Biting Xie et al. This is an open access article distributed under the Creative Commons Attribution License, which permits unrestricted use, distribution, and reproduction in any medium, provided the original work is properly cited.

Evaluation of blasting-induced rock damage and fragmentation is very important for safety control of construction in the jointed rock mass. The discontinuous numerical models are commonly applied due to the advantages in modeling fragmentation and treating discontinuities. In this paper, the rock fracturing algorithm and rate dependent strength law are incorporated into the discontinuous deformation analysis (DDA) to study the wave propagation and rock fragmentation phenomena in dynamic problems. By reproducing Hopkinson pressure bar tests under different loading rates, the improved method is validated to be capable of solving dynamic failure problem. Finally, taking the Xiucun tunnel as an example, its failure process under the action of the explosive wave is simulated, and some failure features are captured. In addition, the explosion wave propagation and its induced particle vibration in surrounding rock are studied. The reasonable simulation results indicate that the modified DDA method can effectively model the stress wave propagation and joint growth process in the jointed rock under blasting load.

\section{Introduction}

Blasting is frequently encountered in rock engineering, and blasting-induced rock failure is an extremely complex mechanical problem. When an explosion occurs in the natural rock mass, a blast shock wave is produced and quickly decays into a blast stress wave, and then the blast stress wave is transmitted and reflected on the existing joint network. Some studies have found that the blast stress wave plays an important role in the fracture and fragmentation of surrounding rock [1-5]. Therefore, when studying the mechanical response and failure behavior of jointed rock caused by explosion, it is of great significance to investigate the propagation and energy attenuation law of blast stress wave. In terms of numerical calculations, due to the advantages in simulating a large number of joints, much work has focused on the discontinuum methods or them coupled with other methods. Lemos [6] used UDEC to study the effect of the bonding force of a single rock joint on the propagation of a one-dimensional shear wave and determined the transmission and reflection coefficients of the shear wave at the joint. Zhao et al. [7] and Chen and Zhao [8] coupled the discrete element program UDEC with the finite difference program AUTODYN-2D to simulate the generation and propagation process of explosion wave in the jointed rock mass. Cai [9] and Zhao [10] used UDEC to study the propagation law of stress waves in single and multiple joints, taking into account the joint linear deformation, nonlinear deformation, shear slip, and other conditions. Wang et al. [11] conducted research on the propagation and attenuation law of longitudinal waves in parallel joints by 3DEC and considered the influence of joint spacing. Jiao et al. [12] introduced nonreflective boundary conditions into the DDA program to simulate the propagation of explosive stress waves in the jointed rock mass.

Although considerable efforts have been made on the propagation of explosion stress waves in jointed rock, 
further research on the rock fracture caused by the stress waves is lacking. Wang and Konietzky [13] introduced a coupled method combining LS-DYNA and UDEC to explore the stress wave induced fracture in jointed rock masses. An et al. [14] implemented a hybrid finite-discrete element method (FEM-DEM) to simulate rock fracture and resultant fragment muck-piling in various blasting scenarios. Ning et al. [15] developed the subblock method of DDA for modeling rock fracturing and blast-induced rock failure and captured the fracturing path and failure pattern of intact rock. These research results show that the discontinuum methods are very promising in simulating explosion-induced rock fracture, but the work done is far from thorough.

Considering that the DDA method inherently has the ability to solve the dynamic problems [16-20] and has a simpler and more straightforward physical meaning than DEM $[21,22]$, it is chosen to study the rock failure caused by the explosion wave in the present paper. By the fracturing algorithm of artificial joint and the dynamic failure criterion related to the strain rate, the ability of the DDA method is extended to dealing with the dynamic fracture and fragmentation of jointed rock. As verification, the extended method is used to model Hopkinson pressure bar tests under different loading rates. Finally, an engineering tunnel case is studied, and the propagation of blast stress waves in jointed rock and its induced fracture behavior of tunnel surrounding rock are analyzed.

\section{The Modified DDA Method}

In 1988, a new numerical model, namely, discontinuous deformation analysis (DDA), is presented by Dr. Shi [23] to study the statics and dynamics of the rock block system. Each block moves according to Newton's second law of motion, and the contacted blocks can open or slide, but not penetrate, which is carried out by contact springs. DDA provides a new powerful tool for simulating the large displacement and failure of rock mass with a large number of joints. As the DDA theory matures and improves, its application in engineering is becoming more and more extensive, mainly involving slope slip, tunnel collapse, dam foundation stability, and so forth.

2.1. DDA Governing Equations. In DDA, the rock mass is considered to be an assembly of blocks separated by joints. The governing equations are derived by minimizing the total potential energy of the block system, which is contributed by the block deformation, block-block contacts, external loads, displacement constraints, and so forth. The governing equations can be written as follows:

$$
M \ddot{D}+\mu \dot{D}+K D=F,
$$

where $M, \mu$, and $K$ are mass, damping, and stiffness matrices, respectively, and $\boldsymbol{D}$ and $\boldsymbol{F}$ denote the generalized displacement vector and generalized force vector. In the present DDA program, damping is not considered, so $\mu=\mathbf{0}$.
Using the forward finite difference scheme and the initial condition, $\ddot{D}$ in equation (1) can be replaced with a function of $\boldsymbol{D}$. Thus, equation (1) can be transformed to

$$
\bar{K} D=\bar{F} \text {. }
$$

Assuming a block system containing $n$ blocks, we have

$$
\begin{aligned}
& \bar{K}=\left[\begin{array}{cccc}
K_{11} & K_{12} & \cdots & K_{1 n} \\
K_{21} & K_{22} & \cdots & K_{2 n} \\
\vdots & \vdots & \vdots & \vdots \\
K_{n 1} & K_{n 2} & \cdots & K_{n n}
\end{array}\right], \\
& D=\left[\begin{array}{c}
D_{1} \\
D_{2} \\
\vdots \\
D_{n}
\end{array}\right], \\
& \bar{F}=\left[\begin{array}{c}
F_{1} \\
F_{2} \\
\vdots \\
F_{n}
\end{array}\right],
\end{aligned}
$$

where $D_{i}, \mathbf{F}_{i}(i=1,2, \cdots, n)$ are $6 \times 1$ submatrices; $\mathbf{D}_{i}$ is the deformation variables of block $i ; F_{i}$ is the generalized force vector distributed to the deformation variables of block $i ; \mathbf{K}_{i j}$ $(i, j=1,2, \cdots, n)$ is a $6 \times 6$ submatrix; $\mathbf{K}_{i i}$ is relevant to the material properties of block $i$; and $\mathbf{K}_{i j}(i \neq j)$ is defined by the contact between blocks $i$ and $j$.

Equation (2) is solved repeatedly to achieve no-penetration state between adjacent blocks by adjusting the contact springs.

2.2. Rock Fracturing Algorithm. In order to extend the research object of DDA from discrete block system to intermittent joint rock and intact rock, the concept of the artificial joint is introduced and developed by Ke [24], Lin et al. [25], and the authors [26]. The rock mass is cut into a triangular block system by real and artificial joints. Further, the fracturing algorithm of artificial joints is put forward by the authors to model the continuous-discontinuous process of the rock mass. The artificial joints bond adjacent blocks together with the cohesive force, which constantly evolves as the rock mass moves and deforms. The normal cohesive force can be depicted as

$$
f_{\mathrm{n}}=\left\{\begin{array}{l}
k_{1} d, \quad\left(d<d_{0}\right), \\
k_{1} d_{0} \frac{d_{\mathrm{c}}-d}{d_{\mathrm{c}}-d_{0}}, \quad\left(d_{0}<d<d_{\mathrm{c}}\right),
\end{array}\right.
$$

where $f_{\mathrm{n}}$ is the normal cohesive force; $k_{1}$ is the stiffness of normal contact spring; $d$ is the opening of the artificial joint, decided by the relative position of adjacent blocks; $d_{0}$ is the joint opening when the cohesive force reaches the maximum tensile force of rock, computed by $\sigma_{t} l / k_{1} ; \sigma_{t}$ is the tensile strength of rock and $l$ is the length of artificial joint; $d_{c}$ is the 
corresponding joint opening while the cohesive force decrease to 0 , obtained by $2 G_{\mathrm{IC}} / \sigma_{\mathrm{t}} ; G_{\mathrm{IC}}$ is the fracture energy of mode I crack.

When the normal cohesive force at an artificial joint decreases to 0 , the artificial joint will cause tensile failure and becomes a real joint. The shear failure of the artificial joint can be judged by the Mohr-Coulomb criterion:

$$
\begin{aligned}
f_{\tau} & =c l+f_{\mathrm{n}} \tan \varphi, \\
c & =\sigma_{\mathrm{c}} \frac{1-\sin \varphi}{2 \cos \varphi},
\end{aligned}
$$

where $f_{\tau}$ is the tangential contact forces and $c$ and $\varphi$ are cohesion and inner friction angle of the rock, respectively.

2.3. Dynamic Failure Criteria. As can be seen from equation (1), the governing equations of DDA are established on Newton's second law of motion, so it is inherently capable of solving dynamic problems. However, the strain rate effect is not considered, which cannot be ignored in certain problems, such as blasting and impact. Some researchers conducted a series of laboratory tests and studied the enhanced effect of loading rate on rock strength. It was generally found that, under the high strain rate caused by explosion, the rock strength rapidly increases as a power function of strain rate. According to the research findings in literature [27], for most brittle materials such as sandstone and granite, the relation between the dynamic tensile and compressive strength of rock and the strain rate is expressed as

$$
\begin{aligned}
& \sigma_{\text {td }}=A \dot{\varepsilon}^{1 / 3}, \\
& \sigma_{\text {cd }}=B \dot{\varepsilon}^{1 / 3},
\end{aligned}
$$

where $\sigma_{\mathrm{td}}$ and $\sigma_{\mathrm{cd}}$ are, respectively, dynamic tensile and compressive strengths of rock; $\dot{\varepsilon}$ is the strain rate; and $A$ and $B$ are the material parameters related to the static strength of rock.

Generally, $A$ and $B$ in formula (6) can be obtained by the regression analysis of test data. For example, according to the tests conducted in literature [27], for sandstone with good integrity and homogeneity, $A=3.75$ and $B=30$. However, the dynamic strength tests are very consuming. In the absence of test data, the empirical formulas for concrete suggested in the design code [28] can be used to estimate the values of brittle rock from the static strengths.

In this study, the above formula is adopted to replace the strength parameters involved in formulas (4) and (5). Thus, they are developed to the dynamic criteria of fracture under blasting load.

\section{Modeling Hopkinson Compression Bar Tests}

Herein, to verify the efficiency of the extended DDA method in considering the strain rate, the Hopkinson compression bar tests of rock-like materials performed in literature [29] are simulated and compared with the test results.

Half-disc specimens with a diameter of $50 \mathrm{~mm}$ are used in the Hopkinson compression bar tests. The specimen contains a $4 \mathrm{~mm}$ long prejoint at the bottom center and a penetrating joint with an inclination of $45^{\circ}$. The distance extending the prejoint tip to the penetrating joint is $8.7 \mathrm{~mm}$. The DDA numerical model is shown in Figure 1, in which the block boundaries displayed in gray are artificial joints. The displacement loading with a certain rate is applied at the incident rod, while the projection rod is fixed.

The physical and mechanical parameters of material are as follows: density $\rho=2600 \mathrm{~kg} / \mathrm{m}^{3}$, elastic modulus $E=5 \mathrm{GPa}$, Poison's ratio $\mu=0.25$, internal friction angle $\varphi=30^{\circ}, A=7$, and $B=40$ in formula (6). The real joints have no strength.

Figure 2 exhibits the final failure patterns of specimens under different loading rates obtained by the improved DDA simulation. It can be discovered that the specimen failure is controlled by the existing joints, while the loading rate significantly affects the dynamic growth of prejoint. When the loading rate is not high enough, the prejoint can only grow along but not through the penetrating joint. As the loading rate increases, the prejoint grows along the penetrating joint for a certain distance and then grows through it. The distance of prejoint growing along the penetrating joint decreases as the loading rate increases. As the loading rate continues to increase, the deformation energy stored in the specimen is too high to be completely consumed by the prejoint growth, resulting in a joint branch. It indicates that the ability of the prejoint growing through the penetrating joint is enhanced by the loading rate. A similar observation was also gained in the experiments of literature [29], as shown in Figure 3.

The simulation results of the improved DDA method agree well with the experiment observations, indicating that it can correctly reflect the rate effect in the dynamic problem and model the failure process of jointed rock under dynamic loading. In addition, the influence of joint orientation on the specimen failure pattern is studied. The loading rate is $0.03 \mathrm{~m} / \mathrm{s}$, and the simulated results are displayed in Figure 4. We can find that, under the same loading rate, with the increase of the angle between the penetrating joint and the loading direction, the ability of the prejoint to propagate through the penetrating joint increases, and the offset distance of the growth path along the penetrating joint decreases.

\section{Modeling the Dynamic Response of Surrounding Rock}

As an engineering case, the Xiucun tunnel in Fujian Province of China is chosen to investigate the mechanical response of jointed rock subjected to multiple blasting loads.

4.1. Xiucun Tunnel. Xiucun tunnel is located in Shaxian County, Fujian Province, China. The maximum buried depth of the tunnel is about $700 \mathrm{~m}$, and the surrounding rock is mainly the early and late Yanshan granite. The rock mass contains several sets of joints nearly parallel to the tunnel axis. The joints are unfilled, smooth, and closed with a dip angle of $60^{\circ} \sim 90^{\circ}$. A computational model of $70 \mathrm{~m} \times 50 \mathrm{~m}$ is 


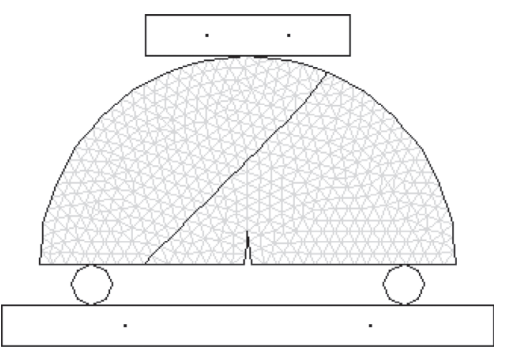

FIgURE 1: Numerical model of the half-disc specimen.

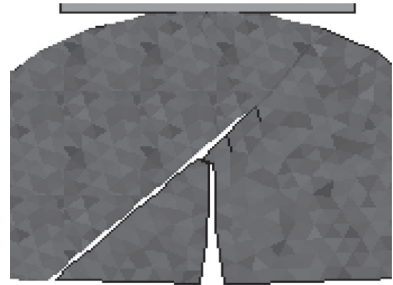

(a)

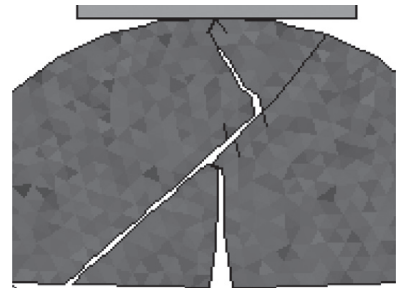

(b)

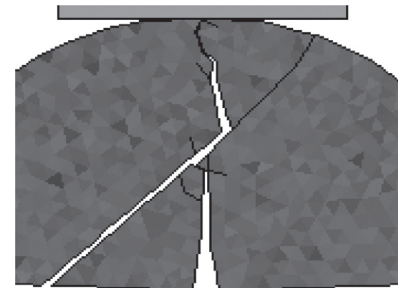

(c)

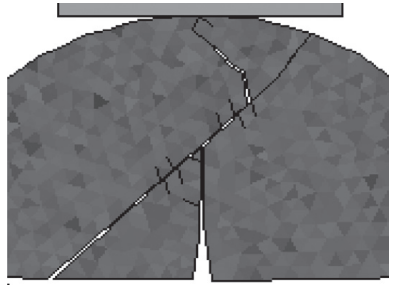

(d)

FIGURE 2: Specimen failure patterns under different loading rates obtained by the improved DDA simulation: (a) $0.02 \mathrm{~m} / \mathrm{s}$; (b) $0.03 \mathrm{~m} / \mathrm{s}$; (c) $0.04 \mathrm{~m} / \mathrm{s} ;$ (d) $0.05 \mathrm{~m} / \mathrm{s}$.

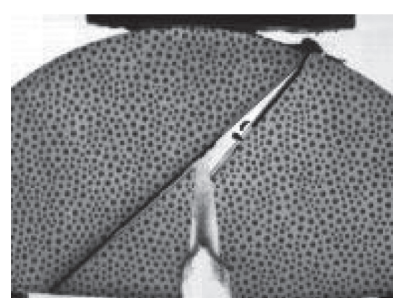

(a)

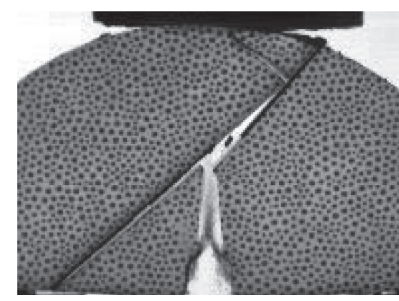

(b)

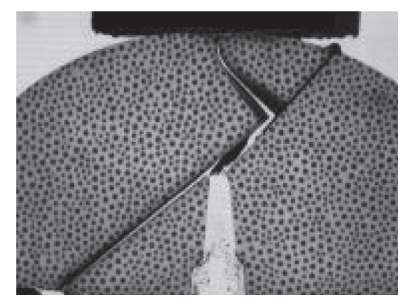

(c)

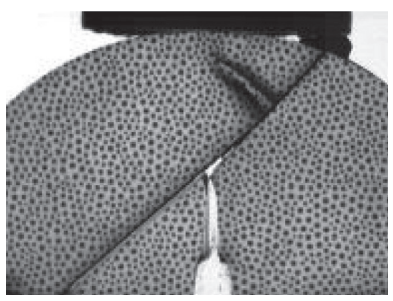

(d)

FIGURE 3: Different failure patterns of specimens obtained in literature [29].

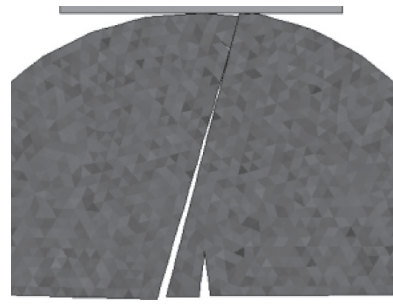

(a)

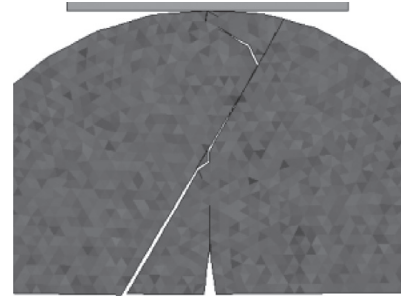

(b)

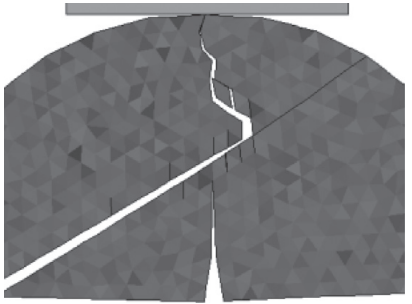

(c)

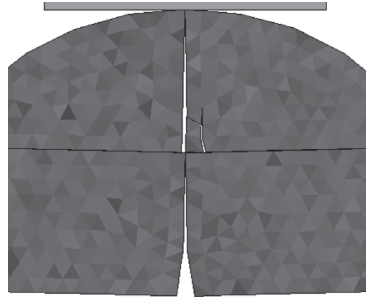

(d)

FIGURE 4: Failure patterns of specimens with different joint orientations under the same loading rate: (a) $15^{\circ}$; (b) $30^{\circ}$; (c) $60^{\circ}$; (d) $90^{\circ}$.

generated; see Figure 5. Two intersecting joint sets with the dip angles of $60^{\circ}$ and $70^{\circ}$ are considered in the model. Each joint set is parallel with the spacing of $9 \mathrm{~m}$, trace length of $22 \mathrm{~m}$, and rock bridge of $2 \mathrm{~m}$. An arched tunnel of $9.4 \mathrm{~m}$ high and $11.7 \mathrm{~m}$ wide is excavated in the intermittent rock mass. The buried depth of the tunnel in this simulation is considered as $100 \mathrm{~m}$. Five measuring points with a spacing of $4 \mathrm{~m}$ are arranged at the right side of the tunnel.

The physical and mechanical parameters of granite are given as density $\rho=2650 \mathrm{~kg} / \mathrm{m}^{3}$, elastic modulus $E=7.4 \mathrm{GPa}$,
Poison's ratio $\mu=0.25$, internal friction angle $\varphi=30^{\circ}, A=4.6$, and $B=8$ in formula (6). The real joints have no strength. The $y$-direction displacements at the bottom of model and the $x$-direction displacements on its both sides are restricted by a large block fixed around the model, and a uniform load of $1.86 \mathrm{MPa}$ is applied to the model top to simulate the overlying rock mass. The horizontal geostress coefficient is about 0.98 , and the initial geostress field is shown in Figure 6. The blasting stress acts vertically on the inner wall of the tunnel. The blasting parameters are as follows: the total 


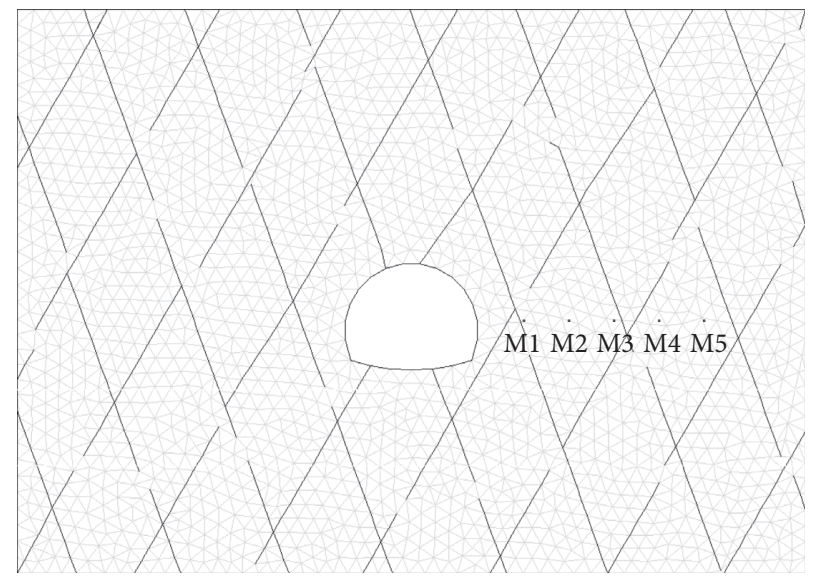

FIgURE 5: Computational model of the Xiucun tunnel.

explosive charge of $186 \mathrm{~kg}$ is detonated in 7 stages, and, in the first stage, the charge of cut holes with the greatest damage to surrounding rock is $12 \mathrm{~kg}$; the explosive density is $1250 \mathrm{~kg} / \mathrm{m}^{3}$, and the detonation velocity of the explosive is $3600 \mathrm{~m} / \mathrm{s}$; the diameters of blast hole and charge are $45 \mathrm{~mm}$ and $32 \mathrm{~mm}$, respectively, and the spacing of blast hole is $500 \mathrm{~mm}$. In this simulation, multiple blasting loads are simplified into three triangle stress waves, and the peak stress can be estimated as $30 \mathrm{MPa}$ from the above blasting parameters [30] (see Figure 7).

\subsection{Explosion Stress Wave Propagation in Surrounding Rock.} Figure 8 compares the particle velocity histories at different monitoring points in the surrounding rock. It can be clearly seen that the near-field particle moves violently, with a peak velocity of $0.77 \mathrm{~m} / \mathrm{s}$, and as the distance of particle away from tunnel increases, the particle motion gradually becomes gentle. Moreover, the moment for the particle velocity reaching the peak value is delayed with distance. Compared to the $0.004 \mathrm{~s}$ at $M 1$ and $M 2$, the arrival time of peak velocity $0.14 \mathrm{~m} / \mathrm{s}$ at $M 5$ is $0.021 \mathrm{~s}$. We also can find that after $0.06 \mathrm{~s}$, the particle motion at the far-field generally stops, indicating that the far-field blasting response is over. Figure 9 plots the blasting vibration velocity curve measured at the tunnel wall, showing the particle motion law close to the numerical results.

Figure 10 shows the attenuation of the peak particle velocity $(P P V)$. There is reason to believe that energy loss occurs when the stress waves traveling across the existing joints. The numerical result agrees well with the empirical findings [31]. The attenuation curve of $P P V$ can be described by a negative power function, as follows:

$$
\mathrm{PPV}=1.442 R^{\prime-1.15}=1.442\left(\frac{R}{\sqrt[3]{\mathrm{Q}}}\right)^{-1.15},
$$

where $R$ is the proportional distance; $R$ is the distance from the explosion source; and $Q$ is the maximum charge in a single stage.

\subsection{Blast-Induced Fracture of Surrounding Rock.} Figure 11 shows the fracture process of Xiucun tunnel's surrounding rock under multiple blasting loads. We can see that, in the initial stage, some radial fractures around the tunnel generate and expand through the existing joints. When they extend a certain distance from the tunnel, they can no longer grow through but along the existing joints. The main reason for this phenomenon is that, as the blasting stress wave propagates and attenuates in the surrounding rock, the loading rate applied on the surrounding rock decreases rapidly, and the energy driving fracture propagation decreases, which in turn causes the ability of the fracture penetrating the existing joints to be weakened. This is consistent with what was observed in the above experiment. From this point of view, the existing joints can restrict the blast crack growth, resulting in a poor blasting effect in the jointed rock mass. As seen in Figure 11(d), a crushing zone restricted by the existing joints is finally formed around the tunnel.

The numerical results show that the depth of the crushing zone is about $4 \mathrm{~m}$, which is consistent with the field test data. Figure 12 plots the sonic velocity-depth curves of the surrounding rock after blasting. The sonic velocity in the surrounding rock around the tunnel drops significantly, showing that the rock mass is destroyed. In the first test, the sonic velocity of surrounding rock within $1.5 \mathrm{~m}$ drops by two-thirds, which is caused by the severe damage to the surrounding rock. In the second test, the sonic velocity further decreases, and the sonic signal of the surrounding rock within $1.7 \mathrm{~m}$ cannot be collected, indicating that the rock mass has been completely broken. According to the technical code [32], if the sonic velocity decreases by more than $10 \%$ after blasting, it can be considered that the surrounding rock is damaged or fractured. Based on this, it can be determined that the depth of blast-induced fracture in the surrounding rock is $3.8 \mathrm{~m}$.

Under the blasting loads, the evolution of fracture number in the surrounding rock is displayed in Figure 13. The total number of fractures is about 450 . Fractures mainly occur in the $0.008 \mathrm{~s}$ of blasting, and the number is about 270 , reaching $60 \%$ of the total. After that, the fracture number increases slowly. It shows that during blasting, the surrounding rock is seriously fractured and its quality drops sharply. Later, some fractures continue to develop and the 


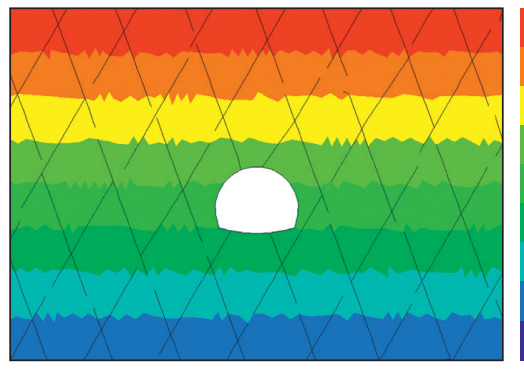

(a)
YY stresses

$-1.83 E+000 \mathrm{MPa}$

$-1.99 E+000 \mathrm{MPa}$

$-2.15 E+000 \mathrm{MPa}$

$-2.31 E+000 \mathrm{MPa}$

$-2.47 E+000 \mathrm{MPa}$

$-2.63 E+000 \mathrm{MPa}$

$-2.79 E+000 \mathrm{MPa}$

$-2.96 E+000 \mathrm{MPa}$

$-3.12 E+000 \mathrm{MPa}$

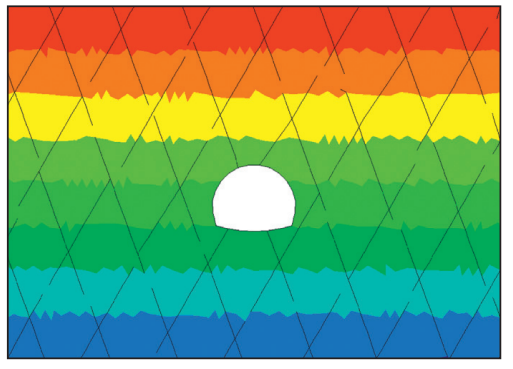

(b)
XX stresses:

$-1.79 E+000 \mathrm{MPa}$

$-1.95 E+000 \mathrm{MPa}$

$-2.11 E+000 \mathrm{MPa}$

$-2.26 E+000 \mathrm{MPa}$

$-2.42 E+000 \mathrm{MPa}$

$-2.58 E+000 \mathrm{MPa}$

$-2.74 E+000 \mathrm{MPa}$

$-2.90 E+000 \mathrm{MPa}$

$-3.06 E+000 \mathrm{MPa}$

Figure 6: The initial geostress field. (a) The vertical geostress. (b) The horizontal geostress.

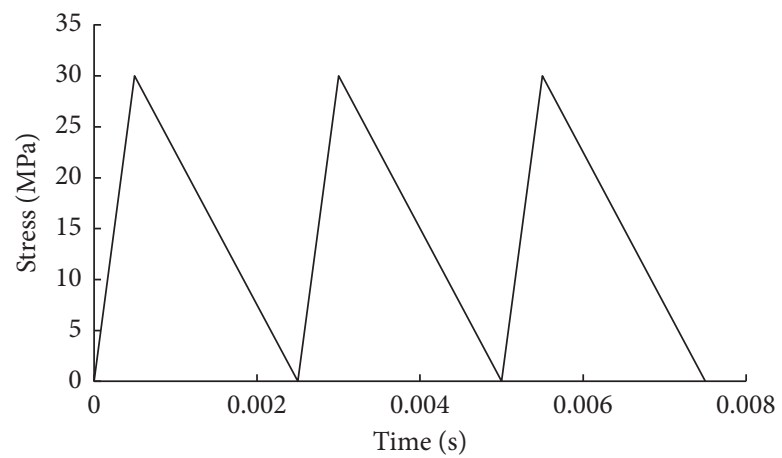

FIgURE 7: Multiple blasting loads acting on the tunnel.

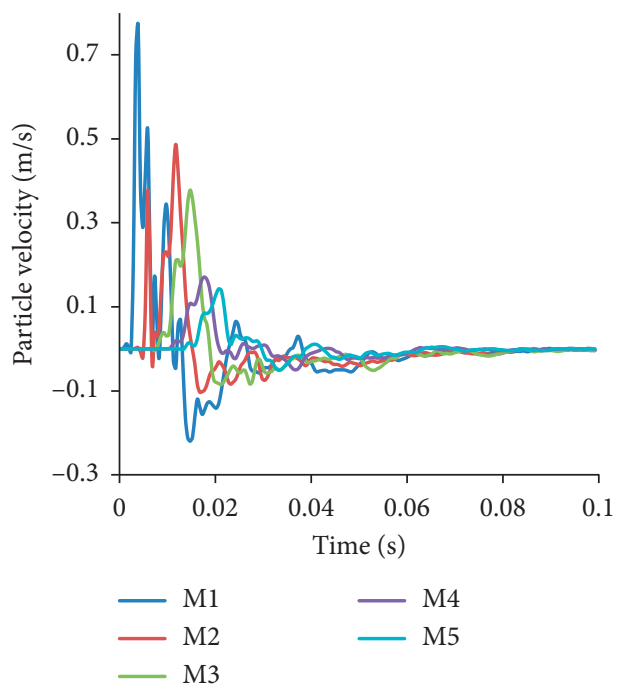

FIGURE 8: Particle velocity histories at different monitoring points.

quality of surrounding rock declines accordingly. It confirms the two sonic test results (Figure 12).

In conclusion, due to the existence of joints, the explosive stress waves undergo complex transmission and reflection, and the stress wave energy is unevenly distributed in the surrounding rock. Where the energy is high, the fracture propagates through the joint, and where the energy is low, the fracture propagates along the joint. Eventually, a failure zone restricted by the joints is formed. Therefore, in blasting design and construction, it is of great significance to accurately grasp the distribution and characteristics of joints in the surrounding rock, for utilizing blasting energy and achieving a good blasting effect. 


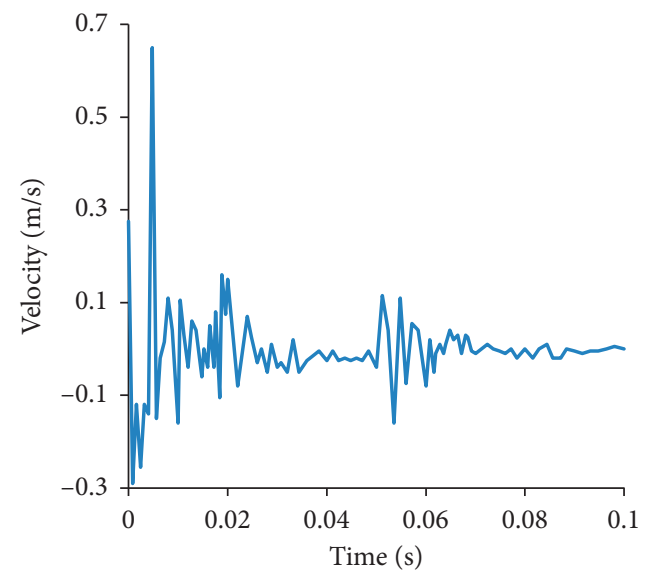

FIGURE 9: Blasting vibration velocity curve measured at the tunnel wall.

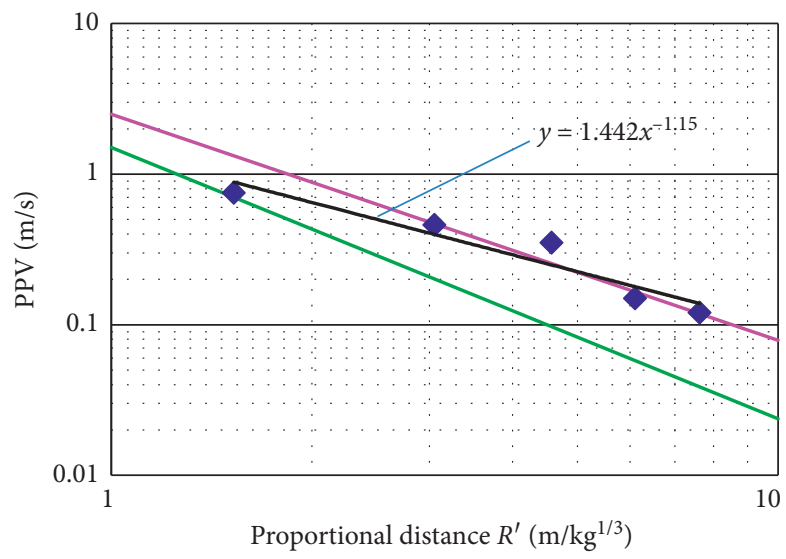

- DDA results

- Upper limit for medium hard rock

— Lower limit for medium hard rock

— Fitting of DDA results

Figure 10: Attenuation curve of $P P V$.

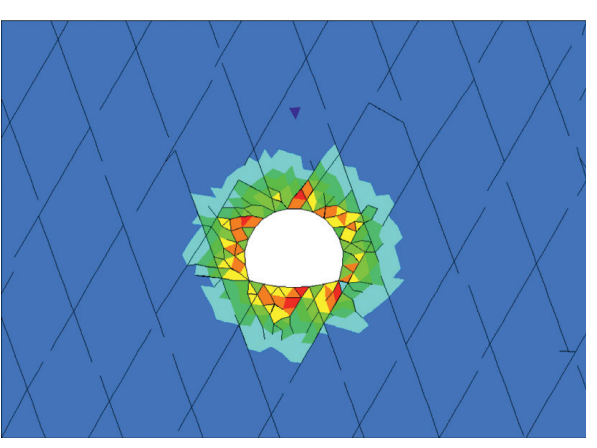

(a)

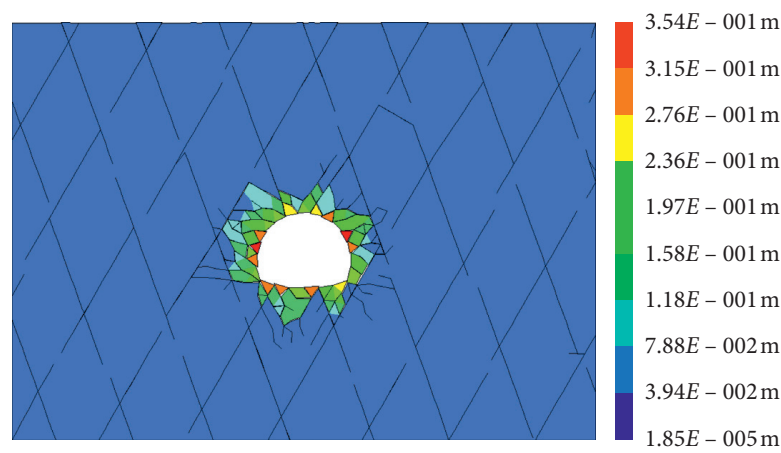

(b)

Figure 11: Continued. 


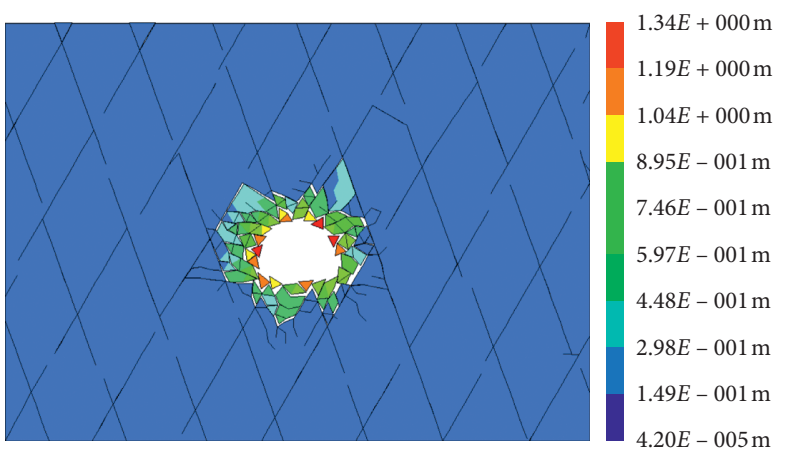

(c)

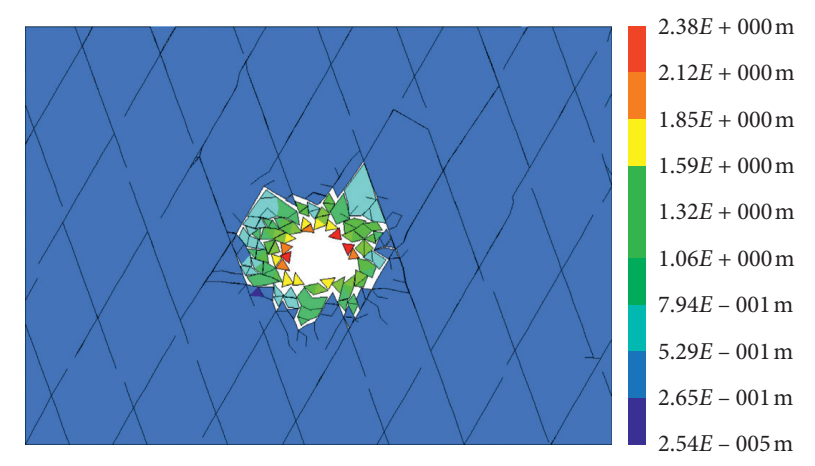

(d)

Figure 11: The failure process of Xiucun tunnel under multiple blasting loads. (a) Displacement distribution at $0.005 \mathrm{~s}$. (b) Displacement distribution at $0.04 \mathrm{~s}$. (c) Displacement distribution at $0.12 \mathrm{~s}$. (d) Displacement distribution at $0.2 \mathrm{~s}$.
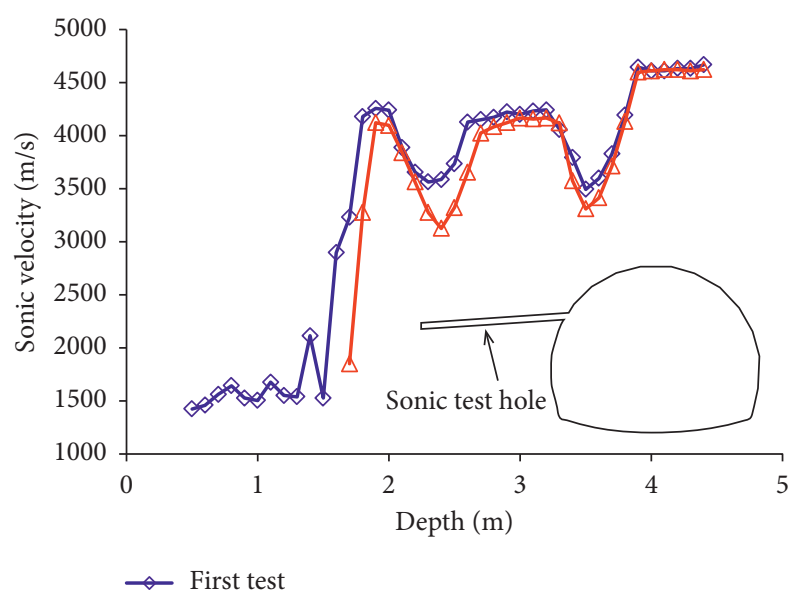

$\triangle$ Second test

FIGURE 12: The sonic velocity-depth curves of surrounding rock after blasting.

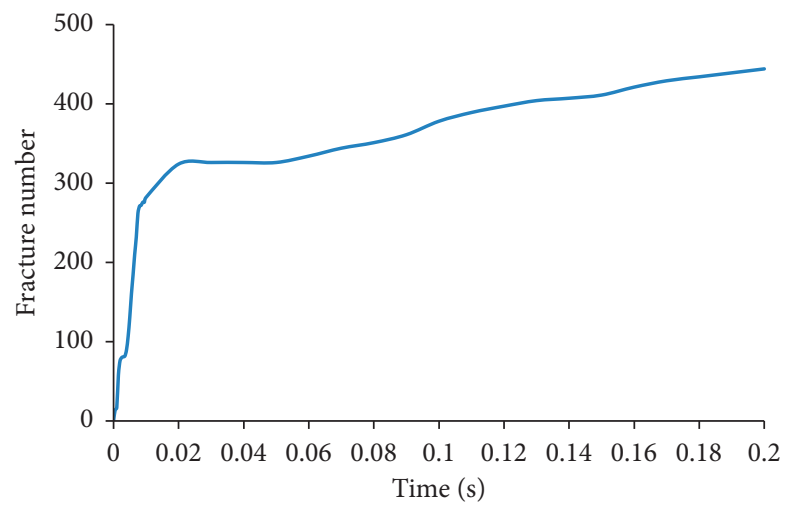

FIgURE 13: The evolution of fracture number in the surrounding rock under the blasting loads. 


\section{Conclusions}

In this paper, for the simulation of the dynamic behavior of jointed rock, a fracture algorithm of artificial joint and a dynamic failure criterion related to strain rate are proposed in the DDA framework.

The proposed method is used to simulate the Hopkinson compression bar tests of the rock-like structure under different loading rates. The simulated results reveal that the loading rate significantly affects the dynamic growth of the prejoint, which agrees well with the experimental observations. It shows that the proposed method can correctly simulate the failure behavior of jointed rock under a high strain rate.

For engineering application, the dynamic response of Xiucun tunnel under multiple blasting loads is studied. The simulated stress wave attenuation law shows a good agreement with the empirical findings. The blasting stress causes radial fractures around the tunnel. The fracture growth mode is closely related to the propagation and distribution of stress wave energy. At the near field of tunnel, the stress wave energy and the loading rate is high, so the fractures grow through the existing joints. While at the far field, the stress wave energy attenuates and the loading rate decreases; thus, the fractures grow along the existing joints. Finally, a fracturing zone restricted by the existing joints is formed. The fracture depth of the surrounding rock is consistent with the sonic test results.

It can be concluded that the improved DDA method can consider the effect of the strain rate in the dynamic problems and study the failure process of rock from continuous to discontinuous at a high strain rate. It provides a tool for solving some complex dynamic failure problems in rock engineering.

\section{Data Availability}

The data used to support the findings of this study are included within the article

\section{Conflicts of Interest}

The authors declare that they have no conflicts of interest.

\section{Acknowledgments}

This study was supported by the National Key Research and Development Program of China (2017YFC1501304) and National Natural Science Foundation of China (41772328 and 11672360).

\section{References}

[1] M. R. Saharan, H. S. Mitri, and J. L. Jethwa, "Rock fracturing by explosive energy: review of state-of-the-art," Fragblast, vol. 10, no. 1-2, pp. 61-81, 2006.

[2] E. Hamdi, J. du Mouza, and J. A. Fleurisson, "Evaluation of the part of blasting energy used for rock mass fragmentation," Fragblast, vol. 5, no. 3, pp. 180-193, 2001.
[3] F. V. Donzé, J. Bouchez, and S. A. Magnier, "Modeling fractures in rock blasting," International Journal of Rock Mechanics and Mining Sciences, vol. 34, no. 8, pp. 1153-1163, 1997.

[4] W. L. Fourney, R. D. Dick, X. J. Wang, and Y. Wei, "Fragmentation mechanism in crater blasting," International Journal of Rock Mechanics and Mining Sciences \& Geomechanics Abstracts, vol. 30, no. 4, pp. 413-429, 1993.

[5] S. McHugh, "Crack extension caused by internal gas pressure compared with extension caused by tensile stress," International Journal of Fracture, vol. 21, no. 3, pp. 163-176, 1983.

[6] J. V. Lemos, A Distinct Element Model for Dynamics Analysis of Jointed Rock with Application to Dam Foundation and Fault motion, Doctoral Dissertation, University of Minnesota, Minneapolis, MN, USA, 1987.

[7] J. Zhao, S. G. Chen, J. G. Cai et al., "Simulation of blast wave propagation in jointed rock mass using UDEC," Journal of China University of Mining \&Technology, vol. 31, no. 2, pp. 111-115, 2002.

[8] S. G. Chen and J. Zhao, "A study of UDEC modelling for blast wave propagation in jointed rock masses," International Journal of Rock Mechanics and Mining Sciences, vol. 35, no. 1, pp. 93-99, 1998.

[9] J. G. Cai, Effects of Parallel Fractures on Wave Attenuation in Rock Masses, Doctoral dissertation, Nanyang Technological University, Singapore, 2001.

[10] X. B. Zhao, Theoretical and Numerical Studies of Wave Attenuation across Parallel Fractures, Doctoral dissertation, Nanyang Technological University, Singapore, 2004.

[11] W.-h. Wang, X.-b. LI, Y.-j. Zuo, Z.-l. Zhou, and Y.-p. Zhang, "3DEC modeling on effect of joints and interlayer on wave propagation," Transactions of Nonferrous Metals Society of China, vol. 16, no. 3, pp. 728-734, 2006.

[12] Y. Y. Jiao, X. L. Zhang, J. Zhao, and Q. S. Liu, "Viscous boundary of DDA for modeling stress wave propagation in jointed rock," International Journal of Rock Mechanics and Mining Sciences, vol. 44, no. 7, pp. 1070-1076, 2007.

[13] Z. L. Wang and H. Konietzky, "Modelling of blast-induced fractures in jointed rock masses," Engineering Fracture Mechanics, vol. 76, no. 12, pp. 1945-1955, 2009.

[14] H. M. An, H. Y. Liu, H. Han, X. Zheng, and X. G. Wang, "Hybrid finite-discrete element modelling of dynamic fracture and resultant fragment casting and muck-piling by rock blast," Computers and Geotechnics, vol. 81, pp. 322-345, 2017.

[15] Y. Ning, J. Yang, X. An, and G. Ma, "Modelling rock fracturing and blast-induced rock mass failure via advanced discretisation within the discontinuous deformation analysis framework," Computers and Geotechnics, vol. 38, no. 1, pp. 40-49, 2011.

[16] Y. H. Hatzor, A. A. Arzi, Y. Zaslavsky, and A. Shapira, "Dynamic stability analysis of jointed rock slopes using the DDA method: king Herod's Palace, Masada, Israel," International Journal of Rock Mechanics and Mining Sciences, vol. 41, no. 5, pp. 813-832, 2004.

[17] X. Fu, Q. Sheng, Y. Zhang, and J. Chen, "Application of the discontinuous deformation analysis method to stress wave propagation through a one-dimensional rock mass," International Journal of Rock Mechanics and Mining Sciences, vol. 80, pp. 155-170, 2015.

[18] X. Peng, P. Yu, Y. Zhang, and G. Chen, “Applying modified discontinuous deformation analysis to assess the dynamic response of sites containing discontinuities," Engineering Geology, vol. 246, pp. 349-360, 2018.

[19] X.-L. Zhang, Y.-Y. Jiao, and J.-F. Ma, "Simulation of rock dynamic failure using discontinuous numerical approach," Computers and Geotechnics, vol. 96, pp. 160-166, 2018. 
[20] F. Zheng, X. Zhuang, H. Zheng, Y.-Y. Jiao, and T. Rabczuk, "Kinetic analysis of polyhedral block system using an improved potential-based penalty function approach for explicit discontinuous deformation analysis," Applied Mathematical Modelling, vol. 82, pp. 314-335, 2020.

[21] J. H. Wu, Numerical Analysis of Discontinuous Rock Masses Using Discontinuous Deformation Analysis, Doctoral dissertation, Kyoto University, Kyoto, Japan, 2003.

[22] L. Zheng, Development of New Models for Landslide Simulation Based on Discontinuous Deformation Analysis, Kyushu University Doctoral dissertation, Fukuoka, Japan, 2010.

[23] G. H. Shi, Discontinuous Deformation Analysis: A New Numerical Model for the Statics and Dynamics of Block system, Doctoral Dissertation, University of California, Berkeley, CA, USA, 1988.

[24] T. C. Ke, Simulated Testing of Two Dimensional Heterogeneous and Discontinuous Rock Masses Using Discontinuous Deformation analysis, Doctoral Dissertation, University of California, Berkeley, CA, USA, 1993.

[25] C. T. Lin, B. Amadei, J. Jung, and J. Dwyer, "Extensions of discontinuous deformation analysis for jointed rock masses," International Journal of Rock Mechanics and Mining Sciences \& Geomechanics Abstracts, vol. 33, no. 7, pp. 671-694, 1996.

[26] Y.-Y. Jiao, X.-L. Zhang, and J. Zhao, “Two-dimensional DDA contact constitutive model for simulating rock fragmentation," Journal of Engineering Mechanics, vol. 138, no. 2, pp. 199-209, 2012.

[27] F. Q. Gong, Experimental Study of Rock Mechanical Properties Under Coupled Static-Dynamic Loads and Dynamic Strength Criterion, Doctoral dissertation, Central SouthUniversity, Changsha, China, 2010.

[28] Thomas Telford Services Ltd, CEB-FIP Model Code 1990, Thomas Telford Services Ltd, London, UK, 1993.

[29] P. Xu, Study on the Interaction between Blast Wave and the Rock Mass with Structural Plane and the Induced Crack Propagation, Doctoral dissertation, Chian University of Mining and Technology-Beijing, Beijing, China, 2017.

[30] Y. Lu and C. Li, "The attenuation law of vibrations in highway tunnel surrounding rocks caused by smooth blasting," Journal of Water Resources and Architectural Engineering, vol. 12, no. 6, pp. 87-92, 2014.

[31] State Administration of Work Safety, Safety Regulations for Blasting, State Administration of Work Safety, China, 2014.

[32] Water Resources and Electric Power Press, Construction Technical Code For Rock Foundation Excavation Engineering of Hydraulic Buildings (Sl47-94), Water Resources and Electric Power Press, Beijing, China, 1994. 